\title{
Ocular Hypertension and Glaucoma after Intravitreal Injection of Triamcinolone Acetonide
}

\author{
Refika Hande Karakahya ${ }^{1}$, Defne Kalayci ${ }^{2}$, Ahmet Karakurt ${ }^{2}$ \\ ${ }^{1}$ Ordu University Training and Research Hospital, Ophthalmology Department \\ ${ }^{2}$ Ankara Numune Training and Research Hospital, Ophthalmology Clinic \\ ${ }^{3}$ Ankara Numune Training and Research Hospital, Ophthalmology Clinic
}

Received: 07 April 2018 Accepted: 11 April 2018, Published online: 20 April 2018

(C) Ordu University Institute of Health Sciences, Turkey, 2018

\begin{abstract}
Objective: The use of intravitreal triamcinolone acetonide (IVTA) for intraocular neovascular, proliferative and edematous diseases has led to an increased incidence of corticosteroid-induced ocular hypertension. Even though largely replaced with anti-vascular endothelial growth factor (anti-VEGF) agents and slow-release dexamethasone implants, boosters are still required in nonresponsive or minimally responsive patients, in cases of tachyplaxis to these agents, or in combination therapies with anti-VEGFs.

Metods: The records of 136 eyes of 124 patients who underwent $4 \mathrm{mg} / \mathrm{ml}$ IVTA treatment for macular edema of variable etiologies of diabetic macular edema, retinal vein occlusions, subretinal choroidal neovascularization, Irvine-Gass Syndrome, retinitis pigmentosa and idiopathic juxtafoveal telengiectasia in the period 2001-2006 were reviewed. Seventy-six eyes of 71 patients of which were followed for at least 3 months were included in the study. The patients were examined at the first day, second week, first month and every month after the injection. Mean intraocular pressure (IOP), IOP exceeding $21 \mathrm{mmHg}$ and percentage of patients exhibiting IOP increase of $5 \mathrm{mmHg}$ after IVTA injection, during the follow-up period were evaluated and compared statistically.

Results: Mean age was $56.64 \pm 12.65$ years and male to female ratio was $35 / 36$. Mean follow-up time was $12.13 \pm 10.30$ months. The mean IOP increased statistically $(\mathrm{p}=<0.001)$ during follow-up from $14.95 \pm 3.15$ $\mathrm{mmHg}$ pre-injection level reaching to a maximum of $21.66 \pm 6.48 \mathrm{mmHg}$ and decreased statistically $(\mathrm{p}=$ $<0.001$ ) to $15.58 \pm 4.16 \mathrm{mmHg}$ at the end of the follow-up. There was no statistical difference between preinjection and post-injection IOP levels $(\mathrm{p}=0.406)$. The IOP levels exceeded $21 \mathrm{mmHg}$ in $46.05 \%$ of the eyes. There was an increase of $5 \mathrm{mmHg}$ and more above the pre-injection level in the $53.94 \%$ of the eyes. Maximum IOP levels were reached at the $2.77 \pm 3.72$ month. In 24 (31.58\%) eyes, topical antiglaucomatous therapy was needed and later 1 eye (4.6\%) required surgical intervention and 1 eye $(4.6 \%)$ required argon laser trabeculoplasty to lower the IOP.

Conclusion: The most common complication following IVTA injections is rise in IOP. Most of these ocular hypertension cases are controllable by medical therapy. However, the risk of glaucoma requiring surgery or long term antiglaucomatous use validate the necessity of a meticulous patient selection and close monitorization of IOP.
\end{abstract}

Key words: intravitreal triamcinolone acetonide, macular edema, steroid-induced glaucoma

Address for correspondence/reprints:

Refika Hande Karakahya

Telephone number: +90 (530) 7778435

E-mail: handekarakahya@yahoo.com
DOI: $10.19127 / \mathrm{mbsjohs.413426}$

Note: This study is presented, as a poster at the combined meeting of 16. Afro-Asian Council of Ophthalmology and 5. Mediterranean Retina Society in İstanbul between13-16 June 2012. 


\section{Introduction}

Triamcinolone acetonide, when injected intravitreally, is an effective agent in the treatment of macular edema secondary to variety of intraocular neovascular, proliferative and edematous diseases such as diabetic retinopathy, central retinal vein occlusion, branch retinal vein occlusion, uveitis, post cataract surgery macular edema, age related macular degeneration (Jonas, 2005). As far as we know no long-term toxic effect of intravitreal triamcinolone injections has been demonstrated. However, the most common side effect following intravitreal triamcinolone acetonide (IVTA) injections is the elevation of intraocular pressure (IOP), occuring up to $52 \%$ of eyes, leading to a secondary chronic open angle glaucoma (Jonas et al., 2003)

Increased IOP can occur as a consequence of oral, intravenous, inhaled, topical, periocular, or intravitreal corticosteroid therapy. The intraocular potency and mode of administration have been shown to be important in initiating an ocular hypertensive response (Gillies et al., 2004; Singh et al., 2004; Smithen et al., 2004). The prolonged effect of triamcinolone is mainly due to its low watersolubility. Triamcinolone can be measured for at least 3 or 18 months after intravitreal injection of 4 $\mathrm{mg}$ or $20-25 \mathrm{mg}$, respectively (Beer et al., 2003).

The exact pathophysiology of steroid induced glaucoma is not entirely understood. The elevation in intra-ocular pressure is thought to be due to increased resistance to aqueous outflow. A rise in IOP following intravitreal steroid injection does occur, and this has been demonstrated by many studies (Beer et al., 2003; Jonas et al., 2003; Smithen et al., 2004). Dynamics of this elevation, especially its extent, onset and interval, is crucial for early detection of IOP rise early and for initiation of immediate and proper treatment to prevent permanent damage to the optic nerve head. In this regard, evaluation of IOP elevation following injection of IVTA for various causes of macular edema is aimed in this study.

\section{Methods}

The records of 136 eyes of 124 patients who underwent $4 \mathrm{mg} / \mathrm{ml}$ IVTA treatment for macular edema of variable etiologies in the period 20012006 at Ankara Numune Training and Research Hospital were reviewed. All patients were fully informed about the potential side effects of the therapy and signed an informed consent.
Eyes with known primary or secondary glaucoma, patients with narrow or closed angles and loss of follow-up before 3 months were excluded from the study. A total of 76 eyes of 71 patients which were followed for at least 3 months, were included in the study. Follow-up time was $12.13 \pm 10.30$ months. A detailed medical history was obtained from each patient and concomitant systemic diseases, previous ocular surgeries, previous laser treatments, if present, were recorded. All of the patients underwent a complete ophthalmologic examination, including uncorrected visual acuity, best-corrected visual acuity, corrective spherical equivalent, IOP, pachymetry, biomicroscopic examination, fundus examination, determination of $\mathrm{C} / \mathrm{D}$ ratio, and fundus fluorecein angiography, perimetry when needed. The IOP measurements were done routinely using a Goldmann applanation tonometer. Gonioscopic examination was performed regularly in all patients before and after the IVTA injection.

The IVTA injections were carried out at the operating room in 53 eyes and at the retina section in 23 eyes, all under aseptic conditions. All patients received topical anesthesia consisted of $0.5 \%$ proparacaine hydrochloride (Alcaine $0.5 \%$, Alcon Pharmaceuticals, Puurs, Belgium) drops applied to the ocular surface 2 times 5 minutes apart before the injection. The periocular skin, eyelid margins and eye lashes were cleaned with $10 \%$ povidone iodine. Following placement of a single-use sterile adhesive surgical ocular drape, disposable lid speculum was inserted. Povidone iodine 5\% was instilled in the conjunctival cul-de-sacs 3 min before the injection. Triamcinolone acetonide (Kenalog, Bristol-Myers Squibb, New York, NY) in dosage of $4 \mathrm{mg} / 0.1 \mathrm{~mL}$ was injected with a 27 gauge needle perpendicularly in the inferior temporal quadrant, $3.5 \mathrm{~mm}$ from the limbus in aphakic/pseudophakic patients and $4.0 \mathrm{~mm}$ in phakic patients with the guidance of a sterile caliper. After removing the needle, a sterile cottontipped applicator was used for a gentle pressure to prevent reflux. Following optic disc and central retinal artery control by indirect ophthalmoscope and hand motion control of the patient, an antibiotic drop was instilled. Slow free-flow anterior chamber paracentesis with a $1 \mathrm{ml}$ insulin syringe needle (26gauge) was executed when required. Patients were instructed to self-administer antibiotic drop 4 times a day during the following 5 days. The patients were examined at the first day, second week, first month and monthly after the injection. Neither angle 
closure nor angle neovascularization developed in any eye during the follow-up period. The preoperative IOP was statistically compared with the postinjection IOPs at different time points. The evaluation was made according to the magnitude of the IOP elevation and the rate at which the IOP dropped to below $21 \mathrm{~mm} \mathrm{Hg}$ in eyes treated with topical medications. The elevation of IOP above 21 $\mathrm{mmHg}$ and the elevation of IOP $5 \mathrm{mmHg}$ above the baseline, the need and the type of surgery performed to lower the IOP in the intractable cases $(>25 \mathrm{~mm}$ $\mathrm{Hg}$ ) were noted. In case of IOP elevation a topical medication to lower the IOP was considered. Betaxolol, dorzolamide, brinzolamide, and the combination of dorzolamide-timolol were the first choices for the topical treatment. The type of surgery undertaken was decided based on the severity of the IOP elevation and the comorbidity of the eye. Statistical analyses were done using SPSS software. Paired $t$ test and Wilcoxon signed rank test were used to compare the mean IOP values at different time intervals. A $\mathrm{p}$ value of $<0.05$ was considered statistically significant.

\section{Results}

Seventy-six eyes of 71 patients, consisting of 36 women and 35 men, which could be followed regularly for at least 3 months, were included in the study. 60 eyes were followed at least 6 months. The mean age of the patients was $56.64 \pm 12.65$. The indications for IVTA injection was macular edema caused by diabetic retinopathy (DRP) in 45 eyes $(59.21 \%)$, retinal venous occlusion (RVO) in 14 eyes $(18.42 \%)$, subretinal choroidal neovascularization in 13 eyes $(17.1 \%), 9$ of which was related to age related macular degeneration (ARMD), Irvine-Gass Syndrome in 2 eyes (2.63\%), retinitis pigmentosa in 1 eye $(1.31 \%)$, idiopathic juxtafoveal telengiectasia in 1 eye $(1.31 \%)$. One eye without a previous important increase in IOP received a second IVTA injection for recurrent diabetic macular edema at postinjection 3 months without any subsequent IOP increase. Besides the IOP elevation, other complications observed following IVTA injection were secondary cataract development in $35.38 \%$ and sterile endophthalmitis in $1.31 \%$.

The mean \pm sd age of the patients in the DRP group was $58.32 \pm 10.53$ with 21 female and 19 male. At least 3 months prior to inclusion in the study 8 eyes had been treated with focal, 5 eyes had been treated with grid and 9 eyes had been treated with both focal and grid laser photocoagulation. Four
(10.0\%) of the patients had type $1 \mathrm{DM}$ and 36 (90.0\%) had type 2 DM. Thirteen $(32.5 \%)$ of the patients also had hypertension. Ten eyes $(22.22 \%)$ were pseudophakic. Mean \pm sd follow-up time was $14.04 \pm 11.73$ months. In the DRP group, preinjection mean visual acuity(VA) was $0.1 \pm 0.11$ and reached to a maximum of $0.30 \pm 0.26$ during follow-up. An increase of $\geq 1$ and $\geq 2$ lines of Snellen VA is observed in $82.23 \%$ and $64.45 \%$ of eyes, respectively. The improvement of visual acuity was statistically significant until 12 months $(\mathrm{p}=<0.0001)$. The time to reach maximum VA was $3.18 \pm 2.80$ months. Macular edema recurred in $19(44.18 \%)$ of 43 eyes. The time that recurrence was first detected after resolution of macular edema was median 6 months. In 1 eye IVTA injection was repeated once. The IOP levels exceeded $21 \mathrm{mmHg}$ in $51.11 \%$ of the eyes in the DRP group. There was an increase of 5 $\mathrm{mmHg}$ and more above the preinjection level in the $57.77 \%$ of the eyes. For the 35 phakic eyes the degree of lens opacification was increased in 16 eyes $(45.71 \%)$. Sterile endophthalmitis was observed in 1 patient.

The mean \pm sd age of the patients in the RVO group was $54.71 \pm 11.72$ with 5 female and 9 male. Three of the patients had CRVO and 11 had BRVO. All of the eyes were phakic. Mean \pm sd follow-up time was $10.42 \pm 7.65$ months. In the RVO group, preinjection mean visual acuity was $0.09 \pm 0.12$ and reached to a maximum of $0.24 \pm 0.25$ during followup. An increase of $\geq 1$ and $\geq 2$ lines of Snellen is observed in $64.28 \%$ and $50.0 \%$ of eyes, respectively. The increase in VA after IVTA injection was statistically significant only in the 6-8 months interval. The time to reach maximum VA was $3.84 \pm 2.95$ months. Macular edema recurred in 4 $(27.57 \%)$ of 14 eyes. The time that recurrence was first detected after resolution of macular edema was median 3.5 months. The IOP levels exceeded 21 $\mathrm{mmHg}$ in $35.71 \%$ of the eyes in the RVO group. There was an increase of $5 \mathrm{mmHg}$ and more above the preinjection level in the $35.71 \%$ of the eyes. For the 14 phakic eyes the degree of lens opacification was increased in 4 eyes (25.57\%). In none of the eyes endophthalmitis did occur.

The mean \pm sd age of the patients in the ARMD group was $66.89 \pm 7.56$ with 4 female and 5 male. All of the eyes were phakic, except one. Mean \pm sd follow-up time was $8.39 \pm 6.90$ months. In the ARMD group, preinjection mean visual acuity was $0.05 \pm 0.06$ and reached to a maximum of $0.11 \pm 0.12$ during follow-up. An increase of $\geq 1$ and $\geq 2$ lines of 
Snellen is observed in $66.67 \%$ and $22.23 \%$ of eyes, respectively. The increase in VA after IVTA injection was statistically significant only in postoperative 1 month $(\mathrm{p}=<0.031)$. The time to reach maximal VA was 3.21 \pm 3.31 months. Macular edema recurred in $71.43 \%$ of the eyes. The mean time that recurrence was first detected after resolution of macular edema was $2.90 \pm 0.54$ months. The IOP levels exceeded $21 \mathrm{mmHg}$ in $33.3 \%$ of the eyes in the ARMD group. There was an increase of $5 \mathrm{mmHg}$ and more above the preinjection level in the $66.6 \%$ of the eyes. For the 9 phakic eyes the degree of lens opacification was increased in 1 eyes $(12.5 \%)$. In none of the eyes endophthalmitis did occur.

The mean IOPs at different follow-up intervals are shown in Table 1. All the eyes including those under topical treatment are included in the analyses.

Table 1. Mean IOPs at follow-up intervals

\begin{tabular}{llllll}
\hline Baseline IOP & $0.5-1 \mathrm{mo}$ & $\mathbf{2 - 4} \mathrm{mo}$ & $\mathbf{6 - 8} \mathrm{mo}$ & $\mathbf{1 0 - 1 2 \mathrm { mo }}$ & $\geq 14 \mathrm{mo}$ \\
\hline $\mathbf{1 4 . 9 5 \pm 3 . 1 5}$ & $14.36 \pm 6.72$ & $19.05 \pm 4.94$ & $18.28 \pm 6.0$ & $15.04 \pm 3.52$ & $12.67 \pm 3.82$ \\
\hline
\end{tabular}

Overall, the mean IOPs increased significantly $(\mathrm{p}=<0.001)$ during follow-up from $14.95 \pm 3.15$ $\mathrm{mmHg}$ pre-injection level reaching to a maximum of $21.66 \pm 6.48 \mathrm{mmHg}$ and decreased significantly $(\mathrm{p}=$ $<0.001)$ to $15.58 \pm 4.16 \mathrm{mmHg}$ at the end of the follow-up. There was no statistically significant difference between pre-injection and post-injection IOP levels $(\mathrm{p}=0.406)$. Maximum IOP levels were reached at the $2.77 \pm 3.72$ month.

In 35 eyes $(46.05 \%)$ IOP was measured to be equal or above $21 \mathrm{mmHg}$. A total of 41 eyes (53.94\%) experienced an IOP rise of $5 \mathrm{mmHg}$ or more compared to baseline preinjection levels. In 24 eyes $(31.58 \%)$, topical treatment was initiated to reduce the IOP when persistent elevation was observed. Subsequent trabeculectomy was needed in 1 of the 24 eyes $(4.16 \%)$ and argon laser treatment in 1 of the 24 eyes $(4.16 \%)$, both of whom were diabetic, to reduce high IOP levels that were refractory to maximal medical therapy with 2 or 3 antiglaucomatous drugs. In both eyes, the IOP returned to below $21 \mathrm{~mm} \mathrm{Hg}$ during the follow-up period after surgery. In the remaining 22 eyes (91.66\%), IOP elevation was responsive to topical medical treatment.

When the levels of IOP increases were compared, no statistically significant difference was found between etiologic subgroups.

\section{Discussion}

Intravitreal injection of long-acting steroids is indicated for the treatment of edematous, inflammatory, and neovascular intraocular diseases (Jonas, 2005). The benefit of intravitreal TA has been addressed in several papers concerned with the treatment of macular edema, however, the exact mechanism remains unclear. There has been a major hypothesis for the mechanism of intravitreal corticosteroid action in inhibiting leukocyte recruitment, thereby, reducing the retinal capillary permeability from blood-retinal barrier (BRB) breakdown and inhibiting the metabolic pathway of vascular endothelial growth factor (VEGF) (Tamura et al., 2005). From the present study, an IVTA injection for macular edema secondary to DRP and RVO provides significant benefits with the onset of a ophthalmoscopic response in macular thickness and VA improvement as soon as 15 days and 2 months for the DRP group, respecctively, and median 1.25 months and 3 months for the RVO group, respectively. This implies that a functional response after the treatment of the edematous retina occurs at a slower rate than does the anatomical response. In the previous studies the clinical effect of IVTA injection for diabetic macular edema over VA were determined according to different acuity charts. Therefore it may not be possible to compare the VA results between studies. The insignificant difference between the baseline VA and the VA seen after 12 months in this study can be explained from a rebound phenomenon of macular edema after a cessation of TA effect. The effect of resolution of macular edema over VA was suggested to be limited if the retinal cellular destruction has occured or if the intercellular structures are damaged by cystoid macular edema. The response to IVTA may be variable among patients according to the extent of macular ischemia, amount of retinal hemorrhages and extent of irreversible photoreceptor loss. Therefore it is difficult to estimate the visual response after resolution of macular edema. This may explain our results of lower and temporary increase in VA despite complete resolution of macular edema in all cases in RVO group. This is consistent with other studies (Cekic et al., 2005). Visual functions may be preserved if IVTA injection can be executed before this irreversible damage develops, in other words as soon as possible. Functional recovery is found lower in this present study in RVO group possibly due to inclusion of cases with CRVO, with much worse prognosis. 
The clinical response of DRP patients to IVTA may be observed faster than RVO patients. IVTA may be an optional pretreatment or adjuvant treatment in cases with diabetic macular edema requiring urgent procedures such as panretinal photocoagulation or cataract extraction that are known to increase macular edema.

One of the major side effects related to intravitreal injection of triamcinolone acetonide, is a steroid induced elevation of IOP. Although the proposed mechanism of corticosteroid-induced IOP elevation is increased resistance to aqueous flow via trabecular meshwork, the precise mechanism is still unknown (Clark and Wordinger, 2009). There are a number of observations that can be simplified into three broad categories: corticosteroids can induce microstructural changes in the trabecular meshwork; cause excess deposition of substances in the trabecular meshwork, decreasing outflow facility; and inhibit proteases and trabecular meshwork endothelial cell phagocytosis causing a decrease in the breakdown of substances in the trabecular meshwork (Jones and Rhee, 2006).

In this study preinjection median IOP was 14 $\mathrm{mmHg}$, the maximum median IOP was $20 \mathrm{mmHg}$ during follow-up. Maximum IOP levels were reached at the $2.77 \pm 3.72$ month. This is consistent with the Mason's study in which triamcinolone was detected 2.75 to 5 months after intravitreal injection of $4 \mathrm{mg}$ (Mason et al., 2004). The median IOP was measured as $15.5 \mathrm{mmHg}$ at the end of the follow-up. IOP increased significantly after IVTA injection compared to pre-injection levels and decreased significantly at the final follow-up interval compared to maximum IOP levels. The statistically significant increase in IOP observed up to 8 months after IVTA injection in this study. There was no statistically significant difference between pre-injection and final post-injection IOP levels.

IVTA injection leads to a significant increase in IOP and magnitude of IOP elevation may vary (Holekamp et al., 2005). In this present study IOP was measured to be equal or above $21 \mathrm{mmHg}$ in $46.05 \%$ of the eyes and $53.94 \%$ of the eyes experienced an IOP rise of $5 \mathrm{mmHg}$ or more compared to pre-injection levels. This mandates close monitorization of IOP following IVTA injection. In several clinical trials IOP after IVTA injection was found to be $21 \mathrm{mmHg}$ or more in 20$70 \%$ of patients (Jonas et al., 2003; Ciardella et al.,2004; Jonas et al, 2004a; Massin et al., 2004; Cekic et al., 2005; Jonas et al., 2005a; Jonas et al, 2005b; Ozkıriş and Erkılıç, 2005.). This wide range of values might be explained by the IVTA dose, variation between definitions of IOP elevation, length of follow-up, sample size, and whether patients have previously received IVTA injections or not. Several reports have suggested the higher frequency of IOP elevation in younger patients, higher baseline IOP, preexisting glaucoma, steroid responsiveness and the type of concurrent eye disease (Jones and Rhee, 2006; Massin et al.,2004; Roth, et al., 2009.). In a meta-analysis, it was shown that there was a tendency toward a higher increase in IOP in patients with uveitis and patients with central retinal vein occlusion (Jonas et al., 2005c). Elevation of IOP commonly occurs as early as 1 day to as late as 12 weeks after the initial treatment. Duration of IOP elevation peaks early, then may normalize. Increase in IOP reaches to maksimum in 1-140 days after IVTA injection (Holekamp et al., 2005).

The role of the dosage of the triamcinolone in IOP increase is controversial (Holekamp et al., 2005, Jonas et al., 2004b, Spandau et al., 2005.). It may be possible to avoid IOP elevations necessitating surgery by screening with topical drops to find out the steroid responders (Breusegem et al.,2009).

Most patients with elevated IOP after IVTA can be successfully managed with topical glaucoma medications (Razeghinejad and Katz, 2012). In this study IOP was controlled by topical medications in $91.66 \%$ of the 24 eyes. Subsequent trabeculectomy was needed in 1 of the 24 eyes (4.16\%) and argon laser treatment in 1 of the 24 eyes $(4.16 \%)$, to reduce high IOP levels that were refractory to maximal medical therapy with 2 or 3 antiglaucomatous drugs. In both eyes the IOP returned below $21 \mathrm{~mm} \mathrm{Hg}$ values during the follow-up period after surgery. These intractable cases may be explained by the presence of diabetes mellitus (Becker et al., 1966). Traditional glaucoma surgical techniques can successfully control elevated IOP and are generally required in less than $2 \%$ of cases. The reported treatment methods for secondary ocular hypertension after IVTA were argon laser trabeculoplasty, selective laser trabeculoplasty, trabeculectomy, cyclodestructive procedures, drainage devices, and pars plana vitrectomy (Agrawal et al.,2004; Kocabora et al., 2008; Razeghinejad and Katz, 2012; Rubin et al, 2008; Viola et al., 2006.). 


\section{Conclusion}

The intravitreal injection of triamcinolone acetonide in a dosage of $4 \mathrm{mg}$ is effective despite leading to secondary ocular hypertension in approximately $50 \%$ of the eyes treated; which is mostly reversible and usually manageable by topical antiglaucomatous medication. However, the risk of glaucoma necessitating permanent antiglaucomatous drug use and of an intractable IOP elevation requiring surgical intervention are points to consider that necessitates a strict control for selection of patient with an IVTA indication and close monitorization of IOP.

Ethics Committee Approval: Approval was received for this study from in Ordu Counseling and Research Center.

Peer-review: Externally peer-reviewed.

Author Contributions: Concept - D.K, A.K, R.H.K; Design D.K, R.H.K; Supervision- D.K, A. K; Materials - R.H.K; Data Collection and/or Processing - R.H.K; Analysis and/or Interpretation - D.K, R.H.K; Literature Review - R.H.K; Writing R.H.K; Critical Review - D.K.

Conflict of Interest: No conflict of interest was declared by the authors.

Financial Disclosure: The authors declared that this study hasn't received no financial support.

\section{References}

Agrawal S, Agrawal J, Agrawal T. Management of intractable glaucoma following intravitreal triamcinolone acetonide. Am J Ophthalmol 2004; 138: 286-287.

Becker B, Bresnick G, Chevrette L, et al. Intraocular pressure and its response to topical corticosteroids in diabetes. Arch Ophthalmol 1966; 76: 477-483.

Beer PM, Bakri SJ, Singh RJ, et al. Intraocular concentration and pharmacokinetics of triamcinolone acetonide after a single intravitreal injection. Ophthalmology. 2003; 110: 681-6.

Breusegem C, Vandewalle E, Van Calster J, et al. Predictive value of a topical dexamethasone provocative test before intravitreal triamcinolone acetonide injection. Invest Ophthalmol Vis Sci 2009; 50: 573-576.
Ciardiella AP, Klancnik J,Schiff W,et al. Intravitreal triamcinolone for the treatment of refractory diabetic macular oedema with hard exudates: an optical coherence tomography study. $\mathrm{Br} \mathrm{J}$ Ophthalmol 2004; 88: 1131-6

Clark AF, Wordinger RJ: The role of steroids in outflow resistance. Exp Eye Res 2009; 88: 752 759.

Cekic O, Chang S, Tseng JJ, et al. Intravitreal triamcinolone treatment for macular edema associated with central retinal vein occlusion and hemiretinal vein occlusion. Retina 2005; 25 : 846850.

Gillies MC, Simpson JM, Billson FA, et al. Safety of an intravitreal injection of triamcinolone: results from a randomized clinical trial. Arch Ophthalmol 2004; 122:336-340.

Holekamp NM, Thomas MA, Pearson A. The safety profile of long-term, high-dose intraocular corticosteroid delivery. Am J Ophthalmol. 2005 Mar;139(3):421-8.

Jonas JB, Kreissig I, Degenring R. Intraocular pressure after intravitreal injection of triamcinolone acetonide. Br J Ophthalmol 2003; 87: $24-27$

Jonas JB, Harder B, Kamppeter BA. Inter-eye difference in diabetic macular edema after unilateral injection of triamcinolone acetonide. Am J Ophthalmol 2004a; 138: 970-77.

Jonas JB, Degenrig RF, Kamppeter BA,et al.Duration of the effect of Intravitreal triamcinolone acetonide.as treatment for diffuse diabetic macular edema. Am J Ophthalmol 2004b; 138: 158-160.

Jonas JB. Intravitreal triamcinolone acetonide for treatment of intraocular oedematous and neovascular diseases. Acta Ophthalmol Scand 2005; 83(6): 645-63.

Jonas JB, Akkoyun I,Kreissig I, Degenring RF. Diffuse diabetic macular edema treated by intravitreal triamcinolone acetonide: comparative non-randomized study. Br J Ophthalmol 2005a: 89: 321-326.

Jonas JB, Akkoyun I, Kamppeter B, et al. Branch retinal vein occlusion treated by intravitreal triamcinolone acetonide. Eye 2005b;19: 65-71.

Jonas JB, Degenring RF, Kreissig I, Akkoyun I, Kamppeter BA. Intraocular pressure elevation after intravitreal triamcinolone acetonide injection. Ophthalmology 2005c; 112: 593-598. 
Jones R 3rd, Rhee DJ. Corticosteroid-induced ocular hypertension and glaucoma: a brief review and update of the literature. Curr Opin Ophthalmol 2006; 17(2): 163-7.

Kocabora MS, Yilmazli C, Taskapili M, et al. Development of ocular hypertension and persistent glaucoma after intravitreal injection of triamcinolone. Clin Ophthalmol 2008; 2: 167-71.

Mason JO 3rd, Somaiya MD, Singh RJ. Intravitreal concentration and clearance of triamcinolone acetonide in nonvitrectomized human eyes. Retina 2004; 24: 900-4.

Massin P, Audren F, Haouchine B, Erginay A, et al. Intravitreal triamcinolone acetonide for diabetic diffuse macular edema. Ophthalmology 2004; 111: 218-225.

Ozkiris A, Erk1lic K. Complications of intravitreal injection of triamcinolone acetonide. Can J Ophthalmol 2005; 40: 63-8.

Razeghinejad MR, Katz LJ. Steroid-induced iatrogenic glaucoma. Ophthalmic Res 2012; 47: 66-80.

Roth DB, Verma V, Realini T, et al. Long-term incidence and timing of intraocular hypertension after intravitreal triamcinolone injection. Ophthalmology 2009; 116: 455-60.

Rubin B, Taglienti A, Rothman RF. The effect of selective laser trabeculoplasty on intraocular pressure in patients with intravitreal steroidinduced elevated intraocular pressure. $\mathrm{J}$ Glaucoma 2008; 17: 287-292.

Singh IP, Ahmad SI, Yeh D, et al. Early rapid rise in intraocular pressure after intravitreal triamcinolone acetonide injection. Am J Ophthalmol 2004; 138: 286-287.

Smithen LM, Ober MD, Maranan L, et al. Intravitreal triamcinolone acetonide and intraocular pressure. Am J Ophthalmol 2004; 138: 740-743.

Spandau UHM, Derse M, Schmitz-Valckenberg P, et al. Dosage dependency of intravitreal triamcinolone acetonide as treatment for diabetic macular edema. Br J Ophthalmol 2005; 89: 9991003.

Tamura H, Miyamoto K, Kiryu J, et al. Intravitreal injection of corticosteroid attenuates leukostasis and vascular leakage in experimental diabetic retina. Invest Ophthalmol Vis Sci 2005; 46: 1440-4.
Viola F, Morescalchi F, Staurenghi G. Argon laser trabeculoplastyfor intractable glaucoma following triamcinolone. Arch Ophthalmol 2006; 124: $133-4$. 